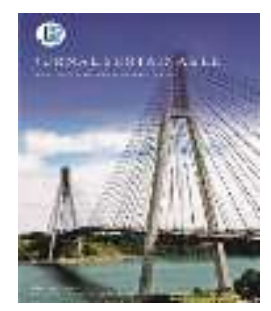

\title{
Aplikasi Peramalan Jumlah Siswa Sekolah Dasar di Kabupaten Tanah Laut Menggunakan Metode Holt's Double Exponential Smoothing
}

\author{
Nora Apriliyani ${ }^{1, *}$, Herfia Rhomadhona ${ }^{2}$, Jaka Permadi ${ }^{3}$ \\ 1,2,3 Jurusan Teknik Informatika, Politeknik Negeri Tanah Laut \\ ${ }^{1,2} \mathrm{Jl}$. A. Yani Km 6 Pelaihari Tanah Laut Kalimantan Selatan \\ *Corresponding Author: nora.apr69@gmail.com
}

\begin{abstract}
Learning processes in the elementary schools at Tanah Laut District is affected by the number of students. Through the number of students can be predicted how much the need of additional teachers, rooms, textbooks and learning medias that support learning processes in the schools. In other words, the infrastructure of the schools can be predicted by the number of students that is registered in Tanah Laut District. The research use Holt's Double Exponential Smoothing method to predicting the number of the prospective students in Tanah Laut District. Mean Absolute Percentage Error (MAPE) technique is used to calculate the percentage of error from the forecasting's result. The system is designed by Entity Relationship Diagram (ERD) and Data Flow Diagram (DFD). The forecasting that have been done said that the number of Tanah Laut's elementary school students at 2018 is 35655 students, with the value of MAPE is about $0.77 \%, \alpha=$ 0.77 and $\beta=0.8$.
\end{abstract}

Keywords - Forecasting application, Holt's Double Exponential Smothing method, Mean Absolute Percentage Error (MAPE).

Intisari-Proses belajar mengajar pada sekolah dasar di Kabupaten Tanah Laut masih dipengaruhi oleh jumlah siswa yang terdaftar. Melalui jumlah siswa yang terdaftar, dapat diketahui berapa banyak kebutuhan akan tenaga pengajar tambahan, ruang kelas, buku ajar dan media ajar yang menunjang proses pembelajaran atau yang dikenal dengan sarana dan prasarana di sekolah tersebut. Sarana dan prasarana merupakan salah satu hal yang membantu kelancaran proses belajar mengajar. Hal ini dapat diketahui dengan memprediksi jumlah siswa yang akan terdaftar pada sekolah-sekolah di Kabupaten Tanah Laut. Pada penelitian ini menggunakan metode Holt's Double Exponential Smoothing untuk memprediksi atau meramal jumlah siswa sekolah dasar di Kabupaten Tanah Laut. Teknik Mean Absolute Percentage Error (MAPE) digunakan untuk menghitung persentase tingkat kesalahan hasil peramalan. Perancangan sistem menggunakan Entity Relationship Diagram (ERD) dan Data Flow Diagram (DFD). Hasil peramalan jumlah siswa sekolah dasar di Kabupaten Tanah Laut pada tahun 2018 berjumlah 35655 siswa, dengan nilai MAPE sebesar $0.770 \%$, nilai $\alpha=0.77$ dan nilai $\beta=0.8$.

Kata kunci-Aplikasi Peramalan, Metode Holt's Double Exponential Smoothing, Mean Absolute Percentage Error (MAPE).

\section{Pendahuluan}

Kabupaten Tanah Laut merupakan salah satu kabupaten yang terletak di Provinsi
Kalimantan Selatan. Kabupaten ini memiliki 11 kecamatan dengan 235 buah sekolah dasar yang tersebar di 11 kecamatan tersebut. Jumlah siswa 
sekolah dasar di Kabupaten Tanah Laut setiap tahunnya ditunjukkan pada Tabel 1 .

Tabel 2. Jumlah siswa SD di Kabupaten Tanah Laut tahun 2006-2017

\begin{tabular}{cc}
\hline Tahun & Jumlah Siswa \\
\hline 2006 & 32864 \\
2007 & 33839 \\
2008 & 34376 \\
2009 & 35425 \\
2010 & 35276 \\
2011 & 35765 \\
2012 & 36185 \\
2013 & 36255 \\
2014 & 36677 \\
2015 & 36508 \\
2016 & 36115 \\
2017 & 35946 \\
\hline
\end{tabular}

Pada Tabel 1 dapat dilihat bahwa jumlah siswa sekolah dasar di Kabupaten Tanah Laut dari tahun 2006 sampai 2017 mengalami beberapa kali peningkatan dan penurunan. Tidak stabilnya jumlah siswa dapat mempengaruhi proses belajar mengajar pada masing-masing sekolah dasar di Kabupaten Tanah Laut. Hal ini dikarenakan jumlah siswa menentukan kapan diperlukannya pengajar tambahan, ruang kelas, buku ajar dan media ajar yang menunjang proses pembelajaran atau yang dikenal dengan sarana dan prasarana di sekolah tersebut. Oleh karena itu pihak sekolah dan pemerintah setempat perlu mencari solusi agar proses pembelajaran pada masing-masing sekolah tidak terhambat dan dapat berjalan dengan baik dan lancar. Salah satu upaya untuk mencegah terjadinya hal tersebut adalah dengan melakukan peramalan jumlah siswa yang akan terdaftar pada sekolah-sekolah di Kabupaten Tanah Laut.

Proses peramalan dapat dilakukan dengan menggunakan beberapa metode, salah satunya adalah dengan menggunakan metode Double Exponential Smoothing yang dikembangkan oleh Holt, yang disebut juga metode Holt's Double Exponential Smoothing. Pada penelitian ini digunakan teknik Mean Absolute Percentage Error (MAPE) untuk menghitung tingkat kesalahan dari hasil peramalan.

\section{Tinjauan Pustaka}

Awwaliyah dan Mahmudah melakukan penelitian yang membandingkan metode
Brown's Double Exponential Smoothing dan metode Holt's Double Exponential Smoothing dalam meramalkan jumlah penderita kusta di Kabupaten Pasuruan tahun 2014. Hasil penelitiannya tersebut menyatakan bahwa nilai MAPE dari metode Holt's Double Exponential Smoothing sebesar 22.47796\%, sementara metode Brown's Double Exponential Smoothing menghasilkan nilai MAPE sebesar $23.3735 \%$. Dengan demikian metode Holt's Double Exponential Smoothing lebih baik daripada Brown's Double Exponential Smoothing dalam peramalan pada kasus tersebut [1].

Adapun acuan dari penelitian lain yaitu penelitian yang dilakukan oleh Hansun dan Subanar yang melakukan penelitian dengan membandingkan metode Weighted Moving Average, metode Holt's Double Exponential Smoothing dan metode Holt's Weigthed Exponential Smoothing Average yang merupakan perpaduan dari metode Weighted Moving Average dan metode Holt's Double Exponential Smoothing dalam meramalkan data indeks komposit Jakarta Stock Exchange (JKSE). Hasil penelitian tersebut menyatakan bahwa nilai rata-rata MSE dari metode Holt's Double Exponential Smoothing sebesar 35448.83 dan nilai rata-rata MAPE dari metode tersebut sebesar $3.83412 \%$ [2].

\section{LANDASAN TEORI}

\section{A. Holt's Double Exponential Smoothing}

Holt's Double Exponential Smoothing merupakan metode yang digunakan untuk memperkirakan data masa depan jika tren muncul pada data time-series [3]. Metode ini menggunakan dua smoothing parameters, yaitu $\alpha$ dan $\beta$. Pada metode ini digunakan persamaanpersamaan berikut.

$$
\begin{gathered}
u_{i}=\alpha y_{i}+(1-\alpha)\left(u_{i-1}+v_{i-1}\right) \\
v_{i}=\beta\left(u_{i}-u_{i-1}\right)+(1-\beta) v_{i-1} \\
y_{i+k}^{\prime}=u_{i}+k v_{i}
\end{gathered}
$$

Keterangan:

$y_{i}$ merupakan nilai asli sesuai waktu $i$.

$\alpha$ merupakan process smoothing constant yang nilainya berkisar dari $0 \leq \alpha \leq 1$. 
$\beta$ merupakan trend smoothing constant yang nilainya berkisar dari $0 \leq \beta \leq 1$.

$u_{i}$ merupakan nilai smoothed constant process terhadap periode waktu $i$.

$v_{i}$ merupakan nilai smoothed trend terhadap periode $i$.

$y^{\prime}{ }_{i+k}$ merupakan nilai perkiraan pada periode $i+k$, dimana $k>0$.

$i$ merupakan periode waktu sekarang.

Pada penelitian yang dilakukan oleh Hansun dan Subanar untuk menentukan nilai $u_{l}$ dan $v_{l}$ digunakan persamaan berikut [2].

$$
\begin{gathered}
\mathrm{u}_{1}=\mathrm{y}_{1} \\
\mathrm{v}_{1}=\mathrm{y}_{2}-\mathrm{y}_{1}
\end{gathered}
$$

\section{B. Mean Absolute Percentage Error (MAPE)}

Nilai Mean Absolute Percentage Error (MAPE) memberikan indikasi tentang berapa banyak rata-rata kesalahan absolut dari data yang diramalkan dibandingkan dengan data aktual dalam bentuk persentase. Kelebihan dari MAPE adalah hasilnya relatif lebih mudah dipahami karena berbentuk persen.

Sebelum menghitung MAPE terlebih dulu menghitung nilai absolut kesalahan peramalan dengan menggunakan persamaan berikut.

$$
e_{i}=y_{i}-y_{i}^{\prime}
$$

Keterangan:

$e_{i}$ merupakan nilai absolut kesalahan peramalan.

$y_{i}$ merupakan data aktual.

$y_{i}^{\prime}$ merupakan data yang diramalkan.

Setelah nilai absolut kesalahan peramalan didapatkan, berikutnya menghitung nilai MAPE dengan persamaan berikut [4].

$$
\text { MAPE }=\frac{\sum_{i}^{n}\left|\frac{E_{i}}{y_{i}}\right|}{n} \times 100
$$

Dimana $n$ merupakan jumlah data testing.

\section{Metode Penelitian}

\section{A. Kerangka Penelitian}

Penelitian diawali dengan melakukan pengumpulan data yang diperoleh dari Dinas Pendidikan dan Kebudayaan Kabupaten Tanah Laut. Data yang dikumpulkan adalah data jumlah siswa SD se-Kabupaten Tanah Laut dari tahun 2006 sampai 2017. Kemudian data-data tersebut (yang disebut dengan dataset) digunakan untuk meramal jumlah siswa pada tahun 2018 dengan menggunakan metode Holt's Double Exponensial Smoothing. Selanjutnya dilakukan pembangunan aplikasi berbasis web dan kemudian aplikasi tersbut diuji dengan menggunakan pengujian blcakbox. Kerangka penelitian dapat dilihat pada Gambar 1 berikut.

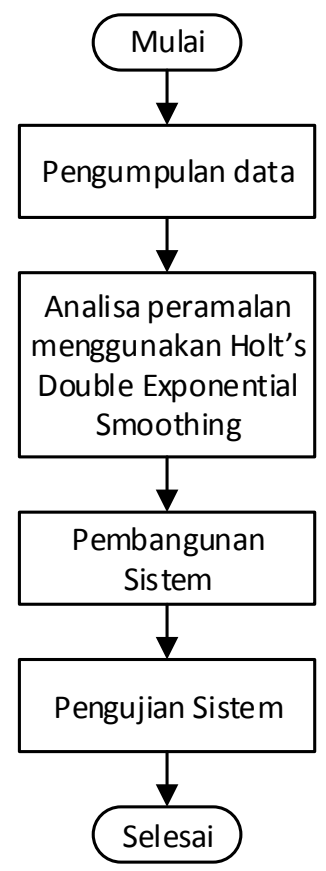

Gambar 1. Kerangka penelitian

\section{B. Metode Pengumpulan Data}

Proses pengumpulan data dilakukan dengan cara studi pustaka dan data yang digunakan adalah data sekunder. Studi pustaka dilakukan dengan mempelajari buku dan jurnal yang melakukan penelitian dengan menggunakan metode Holt's Double Exponential Smoothing. Data sekunder yang digunakan adalah data seluruh sekolah dasar di Kabupaten Tanah Laut berupa NPSN, nama, alamat dan email masing-masing sekolah, daftar sekolah pada masing-masing kecamatan, jumlah siswa yang terdaftar pada masing-masing 
sekolah dasar dari tahun 2006 sampai 2017, jumlah siswa yang terdaftar pada masing-masing kecamatan dari tahun 2006 sampai 2017, dan jumlah siswa yang terdaftar di Kabupaten Tanah Laut dari tahun 2016 sampai 2017. Data tersebut didapatkan dari Dinas Pendidikan dan Kebudayaan Kabupaten Tanah Laut.

\section{Perancangan Sistem}

\section{A. Entity Relationship Diagram (ERD)}

ERD dapat dilihat pada Gambar 2 berikut.

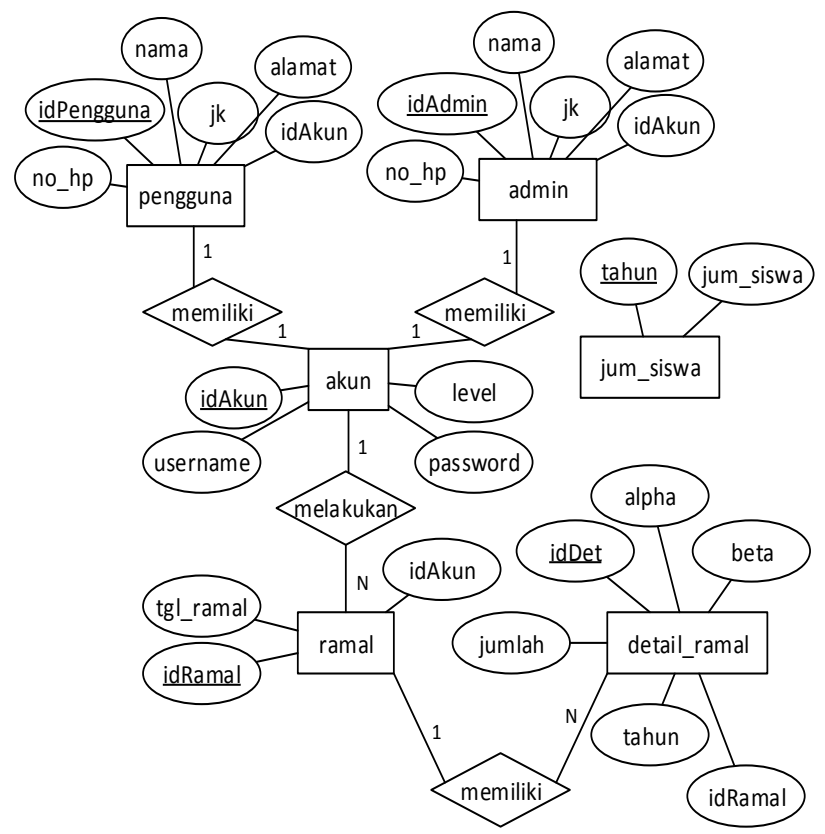

Gambar 2. ERD

Terdapat enam entitas pada ERD yaitu akun, pengguna, admin, ramal, jum_siswa dan detail_ramal.

\section{B. Diagram Konteks (DFD Level 0)}

Diagram konteks atau DFD level 0 dapat dilihat pada Gambar 3.

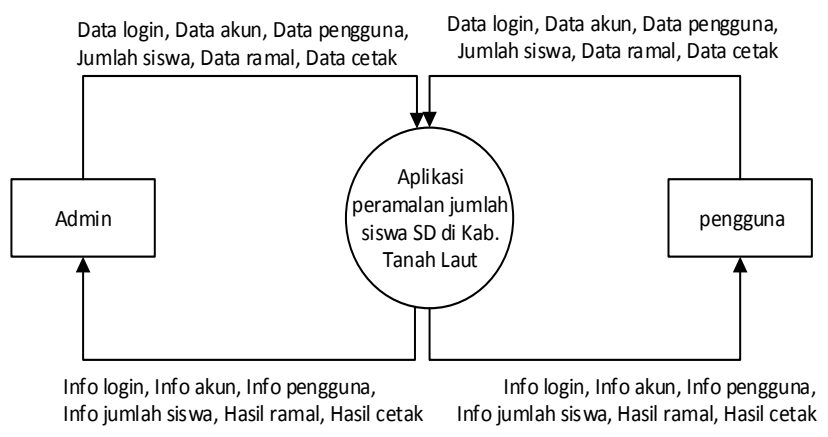

Gambar 3. Diagram konteks (DFD Level 0)
Diagram konteks mendeskripsikan tentang keseluruhan sistem atau gambaran umum sistem yang akan dibuat. Terdapat 2 (dua) level user yang dapat mengakses sistem, yaitu admin dan pengguna. Pengguna adalah pegawai di Dinas Pendidikan dan Kebudayaan Kabupaten Tanah Laut yang diberikan tugas untuk mengelola aplikasi.

\section{Hasil dan Pembahasan}

A. Penerapan Metode Holt's Double Exponential Smoothing pada Peramalan Jumlah Siswa Sekolah Dasar

\section{Metode Holt's Double Exponential} Smoothing diterapkan pada proses peramalan jumlah siswa sekolah dasar sekabupaten Tanah Laut. Data jumlah siswa yang tersedia dari tahun 2006 sampai 2017 yang akan dibagi menjadi $70 \%$ data training dan $30 \%$ data testing, sehingga data yang digunakan sebagai data training adalah data jumlah siswa dari tahun 2006 sampai 2013 dan data yang digunakan sebagai data testing adalah data jumlah siswa dari tahun 2014 sampai 2017. Data jumlah siswa sekolah dasar se-Kabupaten Tanah Laut dari tahun 2006 sampai tahun 2017 dapat dilihat pada Tabel 2.

Tabel 2. Dataset jumlah siswa SD se-Kabupaten Tanah Laut tahun 2006 - 2017

\begin{tabular}{ccc}
\hline Tahun & Jumlah Siswa & Status Data \\
\hline 2006 & 32864 & Data training \\
2007 & 33839 & Data training \\
2008 & 34376 & Data training \\
2009 & 35425 & Data training \\
2010 & 35276 & Data training \\
2011 & 35765 & Data training \\
2012 & 36185 & Data training \\
2013 & 36255 & Data training \\
2014 & 36677 & Data testing \\
2015 & 36508 & Data testing \\
2016 & 36115 & Data testing \\
2017 & 35946 & Data testing \\
\hline
\end{tabular}

Hasil peramalan jumlah siswa sekolah dasar se-Kabupaten Tanah Laut untuk tahun 2018 serta nilai MAPE dengan menggunakan nilai $\alpha$ dan $\beta$ yang dimulai dari 0 dapat dilihat pada Tabel 3 . 
Tabel 3. Nilai MAPE peramalan jumlah siswa seKabupaten Tanah Laut pada tahun 2018

\begin{tabular}{cccc}
\hline $\boldsymbol{N o}$ & $\boldsymbol{\alpha}$ & $\boldsymbol{\beta}$ & $\boldsymbol{M A P E}$ \\
\hline 1 & 0 & 0 & 16.046 \\
2 & 0.11 & 0.1 & 10.670 \\
3 & 0.22 & 0.2 & 6.143 \\
4 & 0.33 & 0.3 & 3.205 \\
5 & 0.44 & 0.4 & 1.706 \\
6 & 0.55 & 0.5 & 1.082 \\
7 & 0.66 & 0.6 & 0.954 \\
8 & 0.77 & 0.8 & 0.770 \\
9 & 0.88 & 0.9 & 0.862 \\
10 & 0.99 & 0.99 & 0.952 \\
\hline
\end{tabular}

Berdasarkan Tabel 3, MAPE terkecil yang didapatkan adalah $0.770 \%$ dengan nilai $\alpha=0.77$ dan nilai $\beta=0.8$, sehingga yang digunakan adalah hasil peramalan dengan nilai MAPE tersebut. Hasil peramalan jumlah siswa sekolah dasar se-Kabupaten Tanah Laut tahun 2018 berdasarkan nilai MAPE terkecil berjumlah 35655 siswa.

Grafik perbandingan data aktual dan hasil peramalan jumlah siswa sekolah dasar seKabupaten Tanah Laut dapat dilihat pada Gambar 4. Data aktual dilambangkan dengan garis berwarna biru dan data hasil peramalan dilambangkan dengan garis berwarna merah.

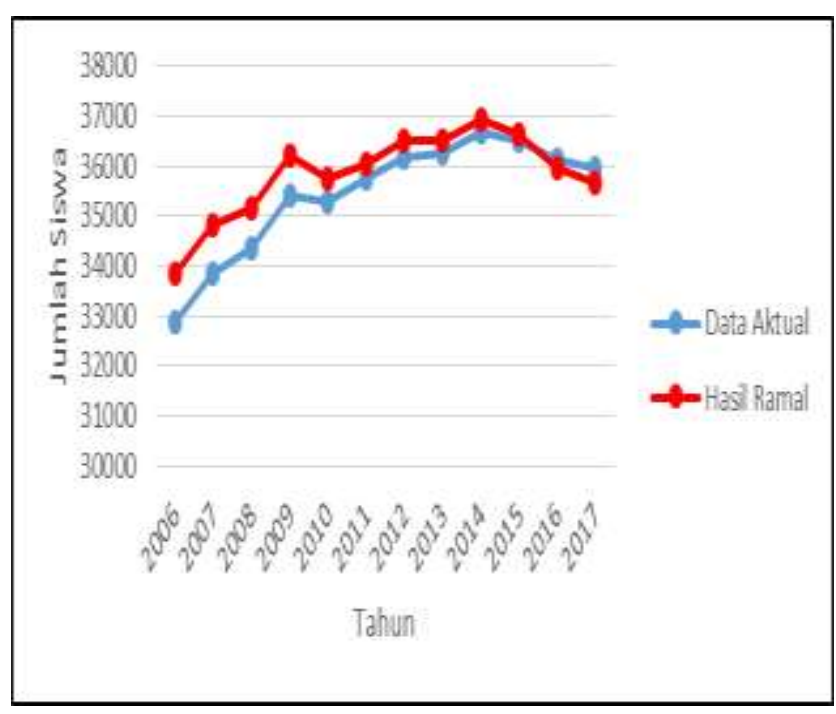

Gambar 3. Grafik perbandingan data aktual dan hasil peramalan

\section{B. Implementasi Aplikasi \\ 1) Halaman Ramal}

Hasil implementasi aplikasi pada halaman ramal dapat dilihat pada Gambar 4.

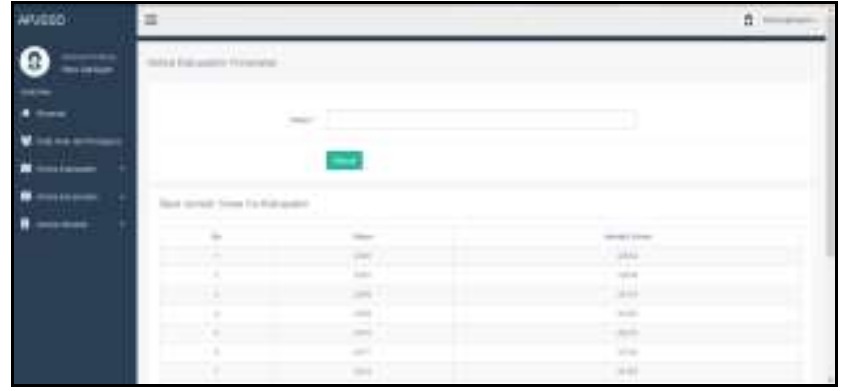

Gambar 4. Implementasi halaman ramal

Pada halaman ini pengguna yang merupakan admin memasukkan tahun yang ingin diramalkan pada kolom input tahun. Setelah memasukkan tahun, admin menekan tombol ramal, kemudian aplikasi akan melakukan proses peramalan dan berpindah ke halaman hasil peramalan untuk menampilkan hasil peramalan.

\section{2) Halaman Hasil Peramalan}

Hasil implementasi aplikasi pada halaman hasil peramalan dapat dilihat pada Gambar 5.

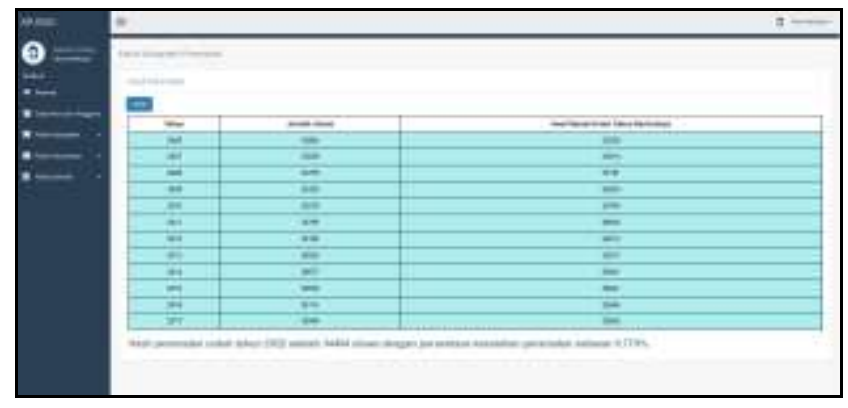

Gambar 5. Implementasi aplikasi halaman hasil ramal

Pada tabel merupakan hasil peramalan siswa dari data training dan data testing. Hasil peramalan yang sesuai dengan tahun yang dimasukkan oleh admin terletak paling akhir di bawah tabel. Hasil akhir menampilkan jumlah siswa dan nilai MAPE dari proses peramalan.

\section{KESIMPULAN}

Berdasarkan pembahasan tentang Aplikasi Peramalan Jumlah Siswa Sekolah Dasar di Kabupaten Tanah Laut Menggunakan Metode Holt's Double Exponential Smoothing maka diperoleh beberapa kesimpulan:

\section{Penerapan metode Holt's Double Exponential} Smoothing pada aplikasi peramalan jumlah siswa sekolah dasar di Kabupaten Tanah Laut menggunakan data jumlah siswa sekabupaten dari tahun 2006 sampai 2013 sebagai data training dan data jumlah siswa se-Kabupaten 
dari tahun 2014 sampai 2017 sebagai data testing. Menggunakan data tersebut maka dapat meramalkan jumlah siswa sekabupaten untuk tahun 2018 dan tahun-tahun berikutnya.

2. Penggunaan teknik MAPE pada hasil peramalan jumlah siswa sekolah dasar di Kabupaten Tanah Laut memperoleh tingkat kesalahan peramalan terkecil sebesar $0.770 \%$ dengan nilai alpha $=0.77$ dan nilai beta $=0.8$. Hasil peramalan dengan nilai MAPE tersebut menghasilkan jumlah siswa sebanyak 35655 siswa pada tahun 2018.

\section{UCAPAN TERIMA KASIH}

Ucapan terima kasih penulis sampaikan kepada semua pihak yang telah membantu. Terutama kepada Dinas Pendidikan dan Kebudayaan Kabupaten Tanah Laut.

\section{REFERENSI}

[1] A. Nurdina, "Penerapan Metode Double Exponential Smoothing dalam Meramalkan Jumlah Penderita Kusta di Kabupaten Pasuruan Tahun 2014," Universitas Airlangga, 2013.

[2] S. Hansun and S. Subanar, "H-WEMA : A New Approach of Double Exponential Smoothing Method," TELKOMNIKA, vol. 14, no. 2, pp. 772-777.

[3] N. Altay and L. A. Litteral, Service Parts Management: Demand Forecasting and Inventory Control. New York: Spriger, 2011.

[4] B. Mahadevan, Operations Management: Theory and Practice. New Delhi: Dorling Kindersley Pvt Ltd, 2010. 